\title{
Constraints and Opportunities of Seri Culture Production in Ethiopia: A Review
}

\author{
Melkam Aleme \\ Ethiopian Institute of Agricultural Research, Tepi Agricultural Research Center, P.O. Box: 34, Tepi, Ethiopia
}

\begin{abstract}
The review summarizes constraints and some opportunities of seri culture production in Ethiopia. The sector is newborn for the country though there are opportunities for the development and enhancing the production and productivity of this cottage agro based industry without immense effecting on environmental conditions because of its environmental friendly perused activity. Some of the constraints like gape of knowledge due to lack of supervision and training by extension workers and governmental or non- governmental organizations, infrastructure, loss of cocoon via pests, agricultural technologies and market access were the most limiting factors for the development of the sector in the country. In other hand there were some opportunities for the sector motivations and working environments. Thus by nature silk production was labor intensive which could implemented by children, old age either women or men near by the house hold and other interested disable bodies because not more need of energy and also the agro climatic condition of Ethiopia is favorable for the rearing of different type of silk worm races as well as the feeding plants like mulberry and castor plants. The review deduced to give attention for the sector by all stock holders from small scale producer to governmental and nongovernmental organizations via, supporting in training, technology, market linkage, transportation and financial support as well as more research inputs could be accessed in the future.
\end{abstract}

DOI: $10.7176 / \mathrm{JBAH} / 10-19-04$

Publication date:October $31^{\text {st }} 2020$

\section{Introduction}

Sericulture is an agro-based and environment friendly cottage industry having incredible employment potential and foreign exchange potentials (Borisade, 2012). It is the production of silkworm for the purpose of raw silk (Rahmathulla, 2012). Silk is called the queen of textiles because of its softness, lustrous, smooth, strong and durability. It is a very coasty filament, obtained from silk worms (Borisade, 2012). Silkworm is one of the most valuable domesticated insects where the growth and development is greatly influenced by weather conditions. Success of silkworm breeds largely depends on their adaptability to the environment in which it is intended to be cultured.

Silk played an important role in the social and religious life of Ethiopia from the earliest days of the Kingdom of Axum. The silk was imported in large quantities from India, Arabia and China and stored in vast grottos in the central highlands of Ethiopia (Metaferia et al., 2007).

However, after long time of history introduction of mulberry silkworm into Ethiopia early in 1930s by Italian and its activities went into recession shortly. Sericulture is new agro business technology for Ethiopia that had been targeted as a tool for poverty reduction. That is why, in most of the region the sector is at infant stage that requires focusing on both biological and physiological aspects. Since the sector has been untapped and lagged behind, research will be thoroughly conducted and hence fill the gaps existed. Even though, realized the suitability of climatic condition for rearing of silk worm and availability of necessary resource in Ethiopia for mulberry and castor plant production and allowed to spread all over the country and mulberry plant is seen growing in altitude of $1500 \mathrm{~m}$ to $2,500 \mathrm{~m}$ in the country. Early 1970 's some Ethiopian scientists were getting interested in mulberry silkworm and they conducted some research works until 1980s. Since then, very few research works have been made due to low priority given by Ethiopian Government (Metaferia et al., 2006).

The biological as well as cocoon-related characters are affected by ambient temperature, rearing seasons, quality mulberry leaf, and genetic constitution of silkworm strains. It is well-established under tropical conditions, unlike poly-voltines, bi-voltines are more vulnerable to various stress like hot weather conditions of tropics, poor leaf quality, and improper management of silkworm crop during summer that is not conducive for bivoltine rearing for technologically and economically poor farmers of India (Lakshmi, 2007 and Begum et al., 2008).

The viability of sericulture sectors depends upon several factors such as the impact of the environmental factors like biotic and abiotic factors is of vital importance. Among the abiotic factors, temperature due to poikilothermic insect and biotic factors like management for rearing ability and silk quality plays a major role on growth and productivity of silkworm (Benchamin and Jolly, 1986).

As a result, failure of timely introduction of adequate technologies, a poor capacity building, lack of integrated and effective extension services, and lack of parent stock of silkworm eggs contributed a lot for the less impact around stakeholders. Also, in case no parent stock of silkworm eggs is domestically produced and as far as it relies on external supply sources, not only a high-quality silkworm egg is hard to be ensured but also it is difficult to 
meet consumer's requirement in terms of timely delivery. Therefore, the objective of this review was to assessed the constraints and opportunities of silk worm production in Ethiopia.

\section{Sericulture in Ethiopia}

Agricultural production in Ethiopia is a subsistence nature of activities. Poverty and unemployment are the main challenges to the country. Poverty alleviation and employment creation, therefore, requires additional on farm and off farm income generation activities like rearing of silkworms (Metaferia et al., 2007). Silk has played an important role in social and religious life of Ethiopia back earliest days of the Kingdom of Axum. This silk was imported in large amount from India, Arabia and China. Emperors would make prodigious gifts of silk to other churches. Ceremonial umbrellas, binding of sacred books, covers for wooden altars and spectacular hangings have all been produced from silk over the centuries. Ethiopia has long been the only major silk weaving region in eastern Africa. The silk yarns used for both art and function were imported from China (Spring and Hudson, 2002).

Ethiopia is granted with diversified climate, vegetation and topography. This is also true for diversified options of sericulture industry which are adopted on different vegetation (for rearing of silk-worms) and different species of silkworms. However, there were no known records of silk being produced in the country until 1930's (Period of colonization). In 1930's, however, the Italians realized the suitability of climatic condition for rearing of silkworms and 4 availability of necessary resources and conducted silkworm rearing at 11 sites though this had been stopped immediately when they left the country (Belli, 1947). There are opportunities of silkworm rearing in different parts of the country if worms are protected against night cold. Later on, visits paid by expatriate professionals also confirmed the immense potential of the country for silk production (Huge, unpublished) and sericulture project was reinitiated jointly by Ethiopian Institute of Agricultural Research and Ministry of Science and Technology in early 2000's and an exciting opportunity for producing silk came in to re-emergence with the introduction of eri and mulberry silkworms from different countries and it adds to the ancient skills of weaving and design in Ethiopia (Metaferia et al., 2007).

\section{Sericulture Production}

The sericulture entails everything from cocoon and raw silk production and business transactions by various processes, such as breeding and maintenance of silkworm races, mulberry breeding and cultivation, silkworm egg production, silkworm rearing and mounting, cocoon drying, silk reeling, raw silk testing, to the production of silk products by manufacturing and weaving, as well as the silk thread and silk industry. The sericulture industry requires much technology and a certain level of investment, and the linkages of a large variety of related businesses. As such, in order to work a sericulture production, organizations and traders who will purchase cocoons produced by sericulture farmers are needed. In other words, before silkworm rearing at sericulture farms can be established, silk reeling companies and brokers to purchase the cocoons are prerequisites. Silk reeling companies must manufacture raw silk of the quality and the price demanded by process manufacturers of the textile industry that use raw silk. In turn, in order to build a silk reeling business, these process manufacturers who will purchase the raw silk and produce silk products for domestic and international demands are needed. A well-established relationship of supply and demand from downstream to upstream, from processed products and sales to sericulture farmers, based on both domestic and international consumption needs, and that can cooperate towards operations growth, is major premise for the establishment of sericulture and silk reeling industry. Domestic demand is especially needed. Hence, cocoons and raw silk must face competition in the international free market, domestic demand is initially important in order to endure the competition. In particular, a unique domestic demand with historical and ethnic characteristics is an important factor for the sericulture industry and its development (JAICAF, 2007).

\section{Opportunities to Sericulture Production Climatic Condition}

In Ethiopia, over all climates is also conducive to expand sericulture as major agro-industry activities. It is also favorable for the growth and development of feeding materials both mulberry and castor plants as well as for the rearing of this feeder silk worm races (JAICAF, 2007). Temperature plays critical role on the growth of the silkworms and their yield parameters regardless of filial generations. This might be due to silkworms being coldblooded animals and hence their physiological activities are highly susceptible to fluctuation of temperature in rearing room. Fluctuation of temperature in rearing room result in low cocoon shell weight. Thus, it is crucial to maintain $25{ }^{\circ} \mathrm{C}{ }^{\circ} \mathrm{C}$ temperature in the rearing room in order to obtain better cocoon shell weight. This result was in line with research findings which states that any temperature outside range of $22-25{ }^{\circ} \mathrm{C}$ during spinning process of Bombyx mori results in poor cocoon shell parameters that shell becomes very loose and folded with wrinkles and knots (Sisodia and Gaherwal, 2017).

Experimental results indicated that cocoon yields of eri silkworm were obtained regularly from early generation until 12th generation which allowed directional selection at $42{ }^{\circ} \mathrm{C}$ and low humidity (50 R.H.) 
(Wangson et al., 2015). When the rearing rooms were adjusted to 25 to $30^{\circ} \mathrm{C}$ optimal production of cocoon and related parameters were obtained. Thus, these rearing temperature conditions are optimal conditions for good quality cocoon production and silkworm seed cocoon selection. Therefore, there are divers' agro ecological conditions in Ethiopia that could be in the range of optimal production of sericulture technology (Endale et al., 2018).

\section{Human Power}

Moreover factors of production like labor and skills are forefront for economic development via sericulture production. Sericulture is most suitable for countries or regions having low labor costs, as it is labor and provides occupation in rural and semi urban areas. The uninterrupted supply of labor force in the country gives an immense opportunity for the development of sericulture and silk industries.

Sericulture will contribute to the growth of a large number of silk industries around the country. The development of industrial sector also contributes to the expansion of employment, output, export and entrepreneurship and in turn helps fulfill the socio-economic objectives of the nation. Sericulture industry will also help balance the regional development especially in rural, semi-urban and backward areas in Ethiopia. It is an agro-based industry; it involves the growing food plants for silkworm and harvesting cocoons, reeling and spinning of cocoon for production of yarn etc. Which will later be value added with various processing and weaving. Sericulture also involves improvement of silk yarn, fabric and generating profitable income for rural poor people.

\section{Challenges of Sericulture Production Agricultural Technologies}

Sericulture requires high level agricultural technologies of including the cultivation of mulberry and silkworm rearing and it was very labor-intensive. Because of these, hardworking farmers with a high level of education and advanced knowledge were needed in the sericulture farming. Furthermore, factors that led to the development of sericulture include the facts that raw silk was an international product and must have been able to respond to the competition with foreign countries, silk needed to compete with the artificial fiber rayon invented at the end of 19th century, and to do so, research on sericulture was intensified and the government focused on dissemination of technology. Also sericulture farmers were eager to learn new techniques in sericulture as a cash crop over subsistence crops. It became clear through the on-site survey in countries like Kenya, Uganda, and Ethiopia, the sericulture industry is now completely inactive in East Africa. In other words, regarding the laboratory scale silkworm eggs production, the small-scale silkworm rearing at sericulture farms, low quality cocoons produced by sericulture farmers and the raw silk reeling from those cocoons as well as the various fabrics attempted to be produced with that raw silk, no clear goals in quality, price, volume, taste and design have been set. This is thought to be the result of the lack of domestic demand in any country in East Africa, and the lack of knowledge and information regarding the current sericulture industry. In other words, the current situation is just the dream of acquiring foreign currency and cash earnings through 12 the export to foreign countries, without any clear thought of consumption needs or target consumers, and without considering the quality, price and design of the cocoons, raw silk and fabric that should be produced. In East Africa, the sericulture industry is in the infant phase, and preparation to start a new industry that has clear and practical goals in mind, such as what kind of demand, what kind of quality and price, and what volume of cocoons and raw silk are currently needed, requires strong national leadership through administrative, financial, and technical support. To do so, expert consideration of the kind of methods needed, long-term promotion planning, and the will to achieve these goals is required. Another important factor for the establishment and promotion of a new sericulture industry is the consideration of conditions such as electricity, service water, management capital, and the sales market because the silk reeling industry which reels raw silk from cocoons is one of manufacturing industries. Added to these conditions, since cocoon production is an agricultural product, it is naturally affected by weather conditions, service water, and the eagerness of the farmers as well. The current conditions in East Africa are considered to be severed disadvantageous in view of each of these conditions. For example, we often heard that the weather in one area was suitable for sericulture, and even saw it in print. However, except for the reference on annual temperature and rainfall by some research centers and that was displayed at the farmer's level; there was nothing to show the temperature and rainfall in the sericulture area. Furthermore, no one locally knew the correct and appropriate rearing temperature for silkworms, or the temperature difference between morning and night in the district or the place which was said to be suitable for silkworm rearing, and even a thermometer, common to any farmer in Japan, could not be observed. When considering sericulture industry in East Africa, issues arising from the lack of domestic demand must be understood, and a future response that reflects that understanding is required. To consider only the technical issues for the improvement of cocoon and raw silk production, without solving issues such as understanding the status of sericulture and silk on the international market, training of sericulture specialists, and consideration of an independent social, financial, and technical environment, further complicate the situation and increases our worries (JAICAF, 2007). 


\section{Lack of knowledge, Marketing of cocoon and related constraints}

Major silkworm raring constraints were lack of knowledge such as training, lack modern house, lack of market availability, lack of governmental and nongovernmental support, lack of silk worm production materials. These problems may lead to poor quality and low amount of silk production. Because of the absence of food plant and lack silkworm farming knowledge the silk production potential of the silk worms are being affected (Alembrhan, 2014).

Marketing of cocoons in a study on economic analysis of seed cocoon production in that all the respondents of multi-voltine cocoon production expressed the incidence of mice as the major problem. Alembrhan (2014) reported on the characteristics and performance of farm entrepreneurs involved in sericulture in Wukro district of North Ethiopia. The problems expressed by Seri culturists were lack of improved mulberry variety inadequate irrigation facility, non-availability of disease free laying in time, lack of separate rearing houses, lack of timely credit, The constraints identified include the incidence of pests (mice) and diseases, water scarcity in the winter months, excess heat in winter.

Alembrhan (2014) identified the constraints in mulberry cultivation and silk cocoon production in their study on problems of sericulture enterprises in Ethiopia. They indicated that the incidence of pest and disease as well as shortage of irrigation water were the major problems in mulberry cultivation. Non availability of separate rearing rooms, shortage of rearing equipment, and mortality and lack of availability of disease-free were the other problems faced by farmers in silk cocoon production. JAICAF (2007) identified, in their study on ethnobotany and production constraints of traditional and commonly used feed of Ethiopia, that the most important constraints in winter and winter feed as lack of irrigation facility and infrastructures, absence of market knowledge, use of improper seeds, high infestations of pests and diseases, postharvest deterioration and lack of effective extension work. Majority of the Seri culturists were not marketed their silk cocoons in the nearby local markets where they lacked traders, market chain and basic infrastructural facilities.

\section{Conclusion and Recommendations}

In Ethiopia sericulture is at infancy with encountered many constraints. However, educated bodies agree that there is a good for the sector to grow in Ethiopia and hence stimulate rural employment and economy of the country. Therefore, feed plants cultivation and silkworm rearing are practiced by a very small number of users and reeling is performed in domestically prepared handloom to reel coarse silk yarn which is not appropriate for the production of quality yarn.

Even though, some opportunities mentioned in the country including the access of human power and diverse climatic conditions still not addressed and reached the attainable production level. From all constraints the availability and access of market would likely the first corner that limits the expansion and acceptance of the technology to grass root level of the community.

This deduced to address the technology for all producers through formal training that can be long term or short terms, coordination of all stock holder for the development of the sector is vital. Filling the gap of knowledge of the producers through hard working and daily supervision of the extension workers and other nearby experts. Financial support also a road to alleviate the production constraints for small to large scale producers.

\section{References}

Alembrhan A.W., 2014. Silkworm Production and Constraints in Eastern Tigray, Northern Ethiopia. International Journal of Innovation and Scientific Research, 10:517-521.

Begum NA R,. Basavaraja HK., Joge PG., and Palit AK., 2008. Evaluation and identification of promising bivoltine breeds in the silkworm, Bombyx mori L, International Journal of Industrial Entomology, 16:15-20.

Benchamin KV., and Jolly MS., 1986. Principles of silkworm rearing. Proc. of Sem. On problems and prospects of sericulture. S.Mahalingam (Ed), Vellore, India, pp 63-106.

Borisade OM., 2012. Training manual on Sericulture as an avenue for youth empowerment in Ekiti State. Training organized by RMR\&DC at Ekiti state sericulture project, Ado Ekiti, Nigeria.

Rahmathulla, VK., 2012. Management of climatic factors for successful silkworm (Bombyx mori L.) crop and higher silk production: A review. Hindaw Publication corporation Psyche. 12:35.

Endale H., Yuehua Z. and Workneh A., 2018. Determination of Optimal Temperature for Production of Quality Eri Silkworm Cocoon and Seed. Agricultural Research and Technology 17(3):75-81.

JAICAF, 2007. Sericulture in East Africa.

Lakshmi H., and Chandrashekharaiah, (2007). Identification of breeding resource material for the development of thermo-tolerant breeds of silkworm, Bombyx mori L, J. Exp. Zool., India, 10:55 - 63.

Metaferia H/Y., Amanuel T., and Kedir Sh., 2006. Scaling up of silk production technologies for employment and income generation in Ethiopia. Proceedings of the International Conference on Scaling Up and Scaling Out of Agricultural Technologies in Ethiopia.

Metaferia H/Y., Amanuel T., and Kedir Sh., 2007. Scaling up of silk production technologies for employment and 
income generation in Ethiopia. In: Success with Value Chain: proceedings of scaling up and scaling out of agricultural technologies in Ethiopia, an international conference, 9-11 May 2006. Ethiopian Institute of Agricultural Research, Addis Ababa.

Sisodia NS and Gaherwal S., 2017. Effects of temperature and relative humidity on commercial product of silkworm (Bombyx mori L) in India. International Journal of Zoology Studies 2(5):52-55.

Wangson D., Sirimungkararat S. and Saksirirat W., 2025. Impruvement of eri silk worm (Samia ricini D.) Tolerant to high temperature and low humidity conditions by continuously regime. Journal of Science and Technology 37(4):401- 408 . 